\title{
The Correlation between Cardiac Enzymes and Cardiotrophin-1 Levels in Patients with Acute Coronary Syndrome
}

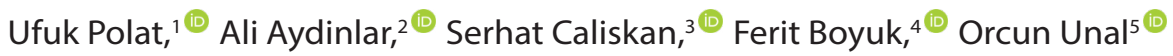 \\ Mustafa Kemal Pasa State Hospital - Cardiology Clinic,' Bursa - Turkey \\ Uludag University Medical Faculty - Department of Cardiology, ${ }^{2}$ Bursa - Turkey \\ Bahcelievler State Hospital - Cardiology Clinic, Istanbul - Turkey \\ Yedikule Thoracic Diseases Education and Research Hospital - Cardiology Clinic, ${ }^{4}$ Istanbul - Turkey \\ Yedikule Thoracic Diseases Education and Research Hospital - Cardiovascular Surgery Clinic, ${ }^{5}$ Istanbul - Turkey
}

\section{Abstract}

Background: In the current era, there is always search for better cardiovascular biomarkers to early diagnose the disease.

Objectives: We aimed to investigate the association between a novel biomarker, cardiothropin-1 (CT-1), and standard markers of myocardial ischemia in patients with acute coronary syndrome (ACS) in Turkey.

Patients and Methods: In this prospective cohort study, patients who were admitted to our institution between July 2012 and July 2013 with the diagnosis of ACS were included. The standard markers of myocardial necrosis and CT- 1 were evaluated at the time of admission and after 6 hours. Changes in laboratory parameters were statistically tested and correlated with routinely used markers of myocardial ischemia. The distribution of the data was analyzed by the Kolmogorov-Smirnov test. Proportional analysis and changes in laboratory parameters were evaluated with Chi-Square test and Fisher Exact test. Statistical significance was defined as $\mathrm{p}<0.05$.

Results: The study enrolled 24 patients (14 male, 10 female) with ST-segment elevation myocardial infarction (STEMI) and 16 patients (9 male, 7 female) with non-ST-segment elevation myocardial infarction (NSTEMI) with elevated cardiac enzymes such as creatine kinase (CK), creatine kinase-MB (CK-MB) and Troponin-T (Tn-T). The average age of the patients was $61.45 \pm 11.04$ years. Increasing CT-1 levels were correlated with the increasing CK ( $\mathrm{p}=0.035$ and $\mathrm{p}=0.018$, respectively), CK-MB ( $\mathrm{p}=0.006$ and $\mathrm{p}=0.096$, respectively), and Tn- $\mathrm{T}$ ( $\mathrm{p}=0.041$ and $\mathrm{p}=0.000$, respectively) at first and at the 6 th hour measurements. The CT-1 values were found to be more increased in the STEMI group $(\mathrm{p}=0.0074)$.

Conclusion: CT-1 is one of the novel biomarkers for cardiac injury. It is correlated with standard markers of myocardial ischemia and the results suggest that CT-1 can be used as a new biomarker.

Keywords: Myocardial infarction; Acute coronary syndrome; Cardiotrophin-1; Atiral fibrillation; Troponin-T.

\section{Introduction}

Cardiovascular diseases are the major causes of mortality and morbidity, especially among the aging population. ${ }^{1}$ Studies have reported that one out of every five deaths in the United States is caused by coronary atherosclerosis. ${ }^{2}$ It is expected that CAD will take the number 1 place in the list of 2020 causes of death prepared by the World Health Organization ${ }^{3}$ Similar studies examining coronary artery disease (CAD) associated mortality in European countries (an average of 30 countries) report that the aforementioned

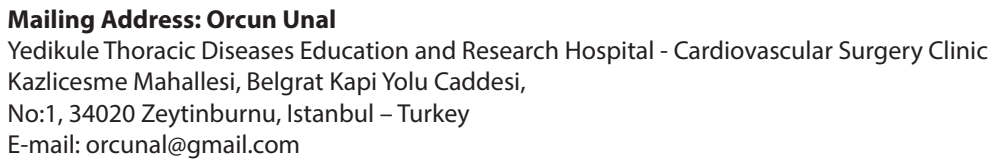


rates among individuals between 45 and 74 years of age were 2.3 per thousand in men and 0.72 per thousand in women. ${ }^{4}$ CAD is a pathological process mainly caused by atherosclerosis. ${ }^{5}$ Other factors such as arteritis may also lead to coronary pathologies. ${ }^{6,7}$ The process starts with fatty streaks in the early stages of life ${ }^{6}$, and ischemia usually results from acute rupture of vulnerable plaques ${ }^{8}$ or as a result of long-lasting decreased coronary blood flow due to increasing coronary obstruction. ${ }^{6}$

The 19-year long follow-up data of the Cardiac Disease and Risk Factors in Turkish Adults (TEKHARF) study determined the CAD associated mortality rate as 7.5 per thousand in men and 3.9 per thousand in women between 45 and 74 years of age. It is obvious that there would be a hike in CAD incidence and recurrent cardiovascular events due to the extension of the average lifespan, increasing treatment options and higher rates of risk factors in senior patients. ${ }^{4}$

Each of the endogenous and exogenous risk factors such as age, gender, smoking, hypercholesterolemia, family history, diabetes mellitus and hypertension significantly increases the risk of CAD. However, there are studies indicating the development of atherosclerosis in some patients with CAD despite the lack of mentioned risk factors. Such findings lead scientists to investigate new risk factors and markers for atherosclerosis (9). Biochemical markers such as C-reactive protein, fibrinogen and homocysteine have been determined to be associated with atherosclerosis already in the past years. ${ }^{9}$

New biomarkers are sought for the early diagnosis of cardiovascular diseases to initiate treatment as early as possible in order to prevent or at least minimize mortality and morbidity, and better quality of life. One of these newly investigated biomarkers in recent years has been Cardiotrophin-1 (CT-1) molecule.$^{10}$

CT-1 is a molecule with many endocrine and paracrine functions beyond being a simple cardiac biomarker. Early detection and follow-up of CT-1 levels may be helpful in predicting cardiac remodeling and determining treatment intensity. ${ }^{11}$ Liao et al., ${ }^{12}$ administered CT-1 to their cohort and showed that CT-1 might have a protective effect against ischemia/reperfusion injury when added before or after stimulated ischemia and re-oxygenation, ${ }^{12}$ Moreover, CT-1 release is increased to protect cardiomyocytes from ischemia and reperfusion injury in case of hypoxia. In a study conducted by Freed et al., authors found that CT-1 levels were high in the infarct area following acute myocardial infarction in mice.$^{13}$
In this study, we sought to investigate the association between CT-1 and other well-known markers of myocardial ischemia in patients with ACS.

\section{Patients and Methods}

The study was conducted with 40 patients between July 2012 and July 2013 in Turkey. Forty patients who were presented to the emergency clinic and diagnosed with acute coronary syndrome (ACS) were included in the research. Exclusion criteria were patients under 18 years of age, with acute renal failure at the time of admission, advanced left ventricular systolic dysfunction (having ejection fraction (EF) of $30 \%$ or less), chronic inflammatory disease, presence of malignancy, presence of acute infection, severe liver failure (alanine aminotransferase (ALT) $>3 X$ upper limit of normal), uncontrolled hypertension (diagnosed with hypertension and having blood pressure values above $140 / 90 \mathrm{mmHg}$ with effective dose medical treatment) or severe mitral and/or aortic valve disease. The study was approved by the institutional medical research ethics committee (ref. no: 2012-13/3, dated July 12, 2012) and conducted in accordance with the Declaration of Helsinki. The patients were transferred to the intensive care unit of the cardiology department and received medical or interventional treatment following being diagnosed with ACS.

A detailed anamnesis was obtained from the patients and their physical examinations were performed. Five cc blood samples for CT-1 measurement were drawn in EDTA-containing tubes in addition to the appropriate amount for routine analysis from each patient from the antecubital fossa veins. Samples were transferred into storage at $-80^{\circ} \mathrm{C}$ at the laboratory. Venous blood plasma samples from patients' admission and 6 hours after admission are incubated in microtiter wells coated with polyclonal anti-human CT-1 antibody.

Electrocardiograms (ECG) and echocardiographies of the patients were evaluated on admission and during the follow-up. Echocardiographies were performed by physicians who were blind to the groups. Patients were divided into three different subgroups of ACS as STEMI (ST-Elevation Myocardial Infarction), NSTEMI (Non-STElevation Myocardial Infarction) and unstable angina pectoris (USAP) according to ECG findings and cardiac enzyme levels.

The development of atrial fibrillation (AF), acute renal failure and death were observed as complications during 
the hospital stay. Also, patients developing acute renal failure, which was determined as 50\% increase in urea/ creatine levels from the admission values were recorded.

\section{Cardiotrophin-1 measurement using the ELISA method}

After a total of 2-hour incubation, biotin-labeled monoclonal anti-human CT-1 antibody was added. Following one hour of incubation, streptavidinhorseradish peroxidase conjugate was added. After a total of 30 minutes of incubation, substrate $\left(\mathrm{H}_{2} \mathrm{O}_{2}{ }^{-}\right.$ tetramethylbenzidine) was added. The reaction was terminated with an acidic solution after 15 minutes of incubation. Absorbance was measured at a wavelength of $450 \mathrm{~nm}$. Absorbance is directly proportional to the CT-1 concentration. CT-1 concentrations of patient samples were calculated by plotting absorbance versus standard concentrations. CT-1 protein levels were read manually by CT- 1 kit, in the DNM-9602 Micro Plate Reader manual reading device. It was read at $450 \mathrm{~nm}$ wavelength by the ELISA method. All data evaluations in the reading process were performed manually.

\section{Statistical Analysis}

Statistical analysis was performed using the Statistical Package for Social Sciences for Windows (SPSS Inc., Chicago, Illinois, USA) 22.00 software. Continuous variables with a normal distribution are described using the average and standard deviation and those that did not show normal distribution is described using the median and interquartile range. Categorical variables are given as number and percentage. The distribution of the data was analyzed by the Kolmogorov-Smirnov test. Normally distributed variables are analyzed with paired samples $\mathrm{T}$ test to compare continuous variables. Continuous values without normal distribution were analyzed with Wilcoxon Signed-Rank test and MannWhitney $\mathrm{U}$ test. Proportional analysis and changes in laboratory parameters in blood drawn at different time intervals were evaluated with Chi-Square test and Fisher Exact test. Pearson correlation was used for analysis of the correlation between the variables. Statistical significance was defined as $\mathrm{p}<0.05$.

\section{Results}

Forty patients were included in the study. There were 23 males and 17 females (57.5\% - 42.5\%, respectively).
The mean age of the patients was $61.45 \pm 11.04$ years. The overall incidence for diabetes mellitus was $27.5 \%$. Hypertension was present in $70 \%$ of the patients. Dyslipidemia which was described as LDL-C $\geq 140 \mathrm{mg} /$ $\mathrm{dL}, \mathrm{HDL}-\mathrm{C}<40 \mathrm{mg} / \mathrm{dL}$, triglycerides $\geq 150 \mathrm{mg} / \mathrm{dL}$ was detected in $12.5 \%$. Among the patients $10 \%$ had a positive family history of heart disease and $37.5 \%$ of the patients were current or former smokers.

There were 24 patients with $\geq 1 \mathrm{~mm}$ ST elevation in at least two leads on the ECG with elevated cardiac enzyme levels, and they were allocated into the STEMI group. Approximately one-third of patients with NSTEMI may have present elevated troponins. ${ }^{14}$ Sixteen patients whose cardiac enzyme levels were elevated without ST elevation (with dynamic ST-T change) were included in the NSTEMI (n: 10) / USAP (n: 6) group (Figure 1). The demographic data of the patients (Patients' age, gender, medical history, smoking habits, diabetes, and hypertension status, familial cardiac history, and the drugs that they are taking) in STEMI and NSTEMI/USAP groups are presented separately in Table 1 and Table 2.

When the CT-1 level distribution in patients with ACS was evaluated in two groups as STEMI and NSTEMI/ USAP, the variability of CT-1 levels in the STEMI group was higher than that of the NSTEMI group (Figure 2).

The blood biochemistry, cardiac enzymes and CT-1 values of the patients were measured at the time of admission and after 6 hours. The mean aspartate aminotransferase (AST) (N: 0-35 U/L), creatine kinase $(\mathrm{CK})(\mathrm{N}: 30-170 \mathrm{U} / \mathrm{L})$ values were found increased at the 6th hour and the increases were found to be statistically significant $(\mathrm{p}<0.01)$. Similarly, creatine kinase-MB (CK$\mathrm{MB}$ ) (N: 5 to $25 \mathrm{IU} / \mathrm{L}$ ) value was increased after 6 hours of admission. Troponin-T (N: 0-0.10 ng/mL (0-0.10 $\mu \mathrm{g} / \mathrm{L}$ ) and CT- 1 values were found increased at the 6 th hour and the increase of the markers were found to be statistically significant $(\mathrm{p}<0.01)$ (Table 3$)$. Hence, myocardial enzymes (CK, CK-MB and Troponin-T) of all patients were significantly increased at the the 6th hour control when compared with the admission values $(\mathrm{p}<0.01)$. Moreover, the CT-1 levels were also increased approximately three folds with respect to admission values at the 6th hour control $(\mathrm{p}<0.01)$.

The CT-1 levels were correlated with the routine biomarkers of CAD, and we detected a statistically significant, positive correlation between Tn-T, CK, CK$\mathrm{MB}$ values, and CT-1 values at the time of admission as well as at the 6 th hour controls (Table 4, Table 5, Table 6). 


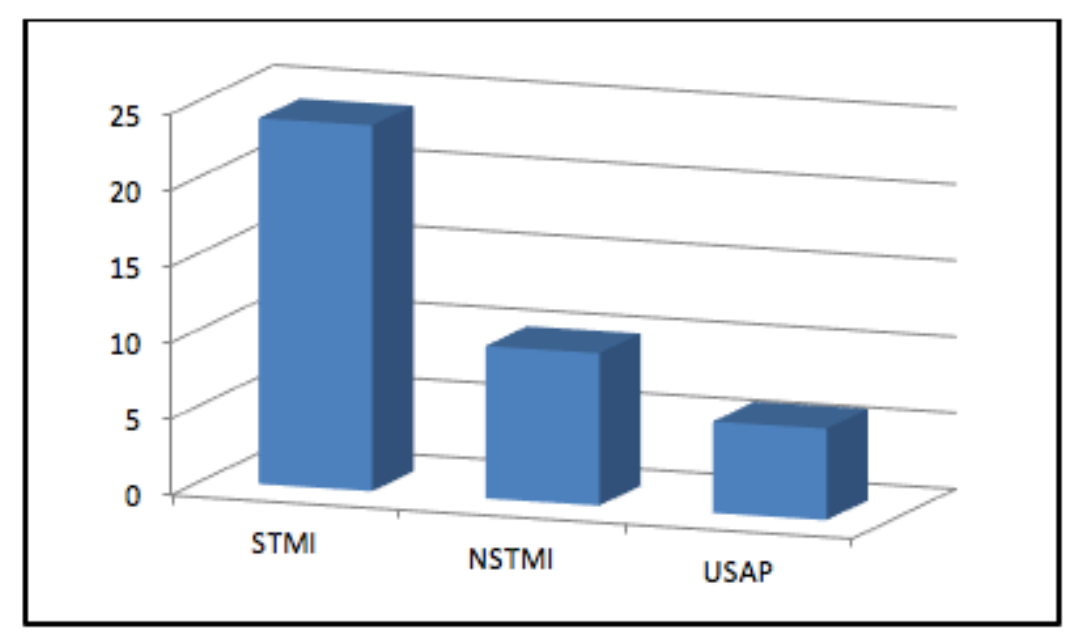

Figure 1 - Patient distribution (ST-segment elevation myocardial infarction (STEMI)/Non-ST-segment elevation myocardial infarction (NSTEMI)/Unstable angina pectoris (USAP)).

\begin{tabular}{lc}
\hline $\begin{array}{l}\text { Table 1 - Demographic and basic clinical characteristics } \\
\text { of patients with STEMI (n: 24) }\end{array}$ \\
\hline $\begin{array}{l}\text { Gender (n, \%) } \\
\text { (male/female) }\end{array}$ & $\mathbf{1 4 / 1 0}(\mathbf{5 8 . 3}, \mathbf{4 1 . 7 )}$ \\
\hline Age (Year) (Mean \pm SD) & $62,25 \pm 8,3$ \\
\hline Diabetes mellitus (n, \%) & $6(25)$ \\
\hline Hypertension (n, \%) & $15(62,5)$ \\
\hline Dyslipidemia (n, \%) & $2(8,3)$ \\
\hline Smoking (n, \%) & $4(16,6)$ \\
\hline Coronary artery disease (n, \%) & $10(41,6)$ \\
\hline Family History (n, \%) & $4(16,6)$ \\
\hline ACE inh/ARB (n, \%) & $17(70,8)$ \\
\hline B-blocker (n, \%) & $5(20,8)$ \\
\hline Statin (n, \%) & $4(16,6)$ \\
\hline Acetylsalicylic Acid (n, \%) & $5(20,8)$ \\
\hline Calcium Channel Blocker (n, \%) & $5(20,8)$ \\
\hline $\begin{array}{l}\text { STEMI: ST-segment elevation myocardial infarction, ACE inh: } \\
\text { Angiotensin-converting enzyme inhibitor, ARB: Angiotensin Receptor } \\
\text { Blocker, B-blocker: Beta blocker }\end{array}$ \\
\hline
\end{tabular}

Coronary angiography was performed in all patients. Percutaneous coronary interventions were performed in 34 patients (22 patients with STEMI, 9 patients with NSTEMI, 3 patients with USAP), 3 patients underwent coronary artery bypass surgery (2 patients with STEMI, 1 patient with NSTEMI) and medical therapy was given to 3 patients ( 3 patients with USAP). Among 40

\begin{tabular}{lc}
\hline $\begin{array}{l}\text { Table 2: Demographic and basic clinical characteristics of } \\
\text { patients with NSTEMI / USAP (n: 16) }\end{array}$ & $9 / 7(56.2,43.8)$ \\
\hline $\begin{array}{l}\text { Gender (n, \%) } \\
\text { (Male/Female) }\end{array}$ & $60.25 \pm 3,5$ \\
\hline $\begin{array}{l}\text { Age (Year) } \\
\text { (Mean } \pm \text { SD) }\end{array}$ & $5(31.2)$ \\
\hline Diabetes mellitus (n, \%) & $13(81.2)$ \\
\hline Hypertension (n, \%) & $3(18.7)$ \\
\hline Dyslipidemia (n, \%) & $0(0)$ \\
\hline Smoking (n, \%) & $5(31,2)$ \\
\hline Coronary artery disease (n, \%) & $7(43.7)$ \\
\hline Family History (n, \%) & $9(56.2)$ \\
\hline ACE inh/ARB (n, \%) & $2(12.5)$ \\
\hline B-blocker (n, \%) & $7(43.7)$ \\
\hline Statin (n, \%) & $7(43.7)$ \\
\hline Acetyl Salicylic Acid (n, \%) & $5(31.2)$ \\
\hline Calcium Channel Blocker (n, \%) & \\
\hline $\begin{array}{l}\text { NSTEMI: non-ST segment elevation myocardial infarction, ACE inh: } \\
\text { Angiotensin-converting enzyme inhibitor, ARB: Angiotensin Receptor }\end{array}$ & \\
\hline Blocker &
\end{tabular}

patients diagnosed with ACS, 4 patients developed new-onset AF during hospitalization. Although the general features (gender, family history, smoking habits) of these 4 patients with newly diagnosed AF did not differ from the non- AF population, hypertension and $\mathrm{CAD}$ on angiography were significantly more prevalent in these cases (Table 7). Moreover, the Tn-T 


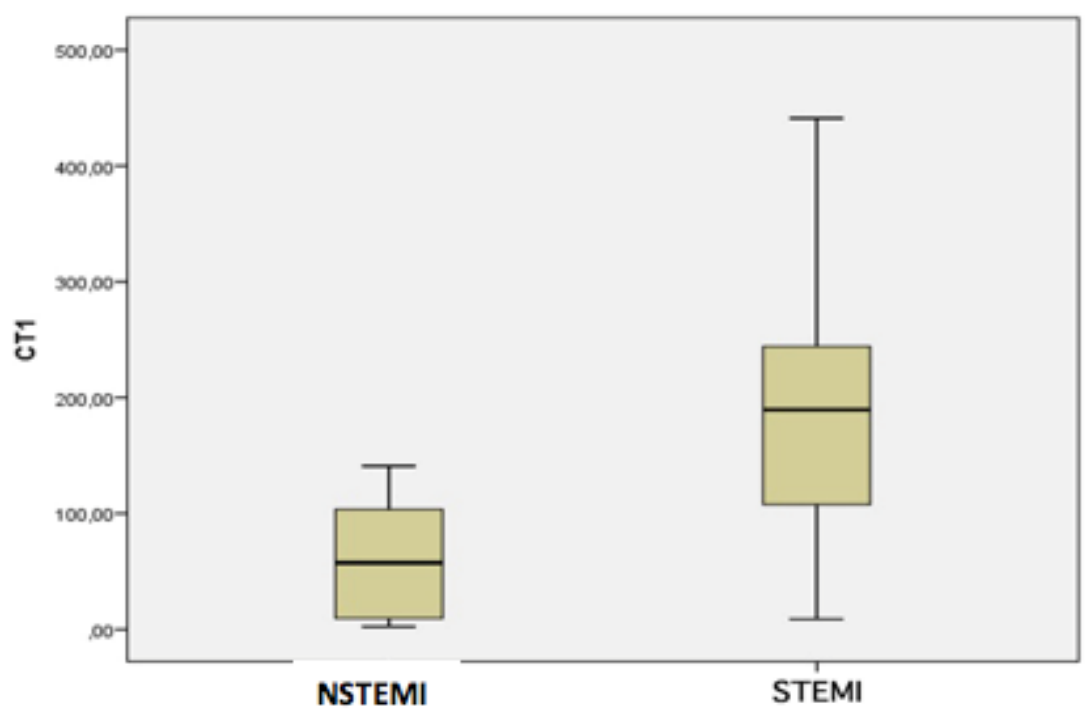

Figure 2 - Distribution of CT-1 levels in patients with acute coronary syndrome (ACS).

CT1: Cardiotrophin-1; NSTEMI: Non-ST-elevation myocardial infarction; STEMI: ST-elevation myocardial infarction.

Table 3 - Changes in laboratory values at 0 and 6 hours of all subjects included in the study

\begin{tabular}{|c|c|c|c|}
\hline & 0. hour & 6. hour & $\mathrm{p}$ value \\
\hline WBC (K/Ml) & $10.68 \pm 4.01$ & $11.62 \pm 3.29$ & $0.024^{*}$ \\
\hline HG (g/dl) & $12.90 \pm 1.77$ & $12.46 \pm 1.84^{*}$ & 0.022 \\
\hline AST (IU/L) & $48.77 \pm 13.34$ & $56.45 \pm 18.32$ & $0.0045^{*}$ \\
\hline ALT (IU/L) & $26.85 \pm 11.89$ & $29.13 \pm 8.01$ & $0.0071^{*}$ \\
\hline CK (IU/L) & $\begin{array}{c}\text { Range: } 254-493 \\
\text { Median: } 372.5\end{array}$ & $\begin{array}{c}\text { Range: } 416-829 \\
\text { Median: } 712.3\end{array}$ & $0.0082^{* *}$ \\
\hline CK-MB (IU/L) & $48.08 \pm 24.5$ & $90.18 \pm 33.14$ & $0.0065^{*}$ \\
\hline Tn-T (ng/mL) & $\begin{array}{c}\text { Range: } 1354-2462 \\
\text { Median: } 1758.4\end{array}$ & $\begin{array}{c}\text { Range: } 2519-6128 \\
\text { Median: } 4732.6\end{array}$ & $0.0092^{* *}$ \\
\hline CT-1 (pg/mL) & $132.04 \pm 48.1$ & $322.19 \pm 98.12$ & $0.0084^{*}$ \\
\hline
\end{tabular}

WBC: White blood cell count, HG: Hemoglobin, AST: Aspartate amino transferase, ALT: Alanine amino transferase, CK: Creatine kinase, CK-MB: Creatine kinase-Muscle Brain, Tn-T: Troponin-T, CT-1: Cardiotrophin-1, $p<0.01$ statistically significant.

*: paired T-test was used, **: Wilcoxon Signed-Rank test was used.

values at the time of admission were higher in the $\mathrm{AF}$ group $(\mathrm{p}<0.01)$. However, the CT-1 values were not significantly different in patients developing $\mathrm{AF}$ and the remaining patients without $\mathrm{AF}$ (Figure 3 ) which was attributed to the small number of patients with the AF group (4 patients).

During the follow-up of the patients in the coronary intensive care unit, complete atrioventricular block developed in 2 patients and rhythm control was achieved with temporary cardiac pacemakers. One patient developed nodal rhythm. There was no need for a permanent pacemaker. One patient developed ventricular tachycardia and with electrical cardioversion rhythm control was achieved (Figure 4).

Mortality occurred in 1 patient with acute myocardial failure and renal insufficiency (cardiorenal syndrome). Cardiorenal syndrome was developed during the follow-up period in the coronary intensive care unit. Hemodynamic stability was achieved with inotropic and intra-aortic balloon pump support. Hemodialysis was necessitated and adequately performed. Unfortunately, 


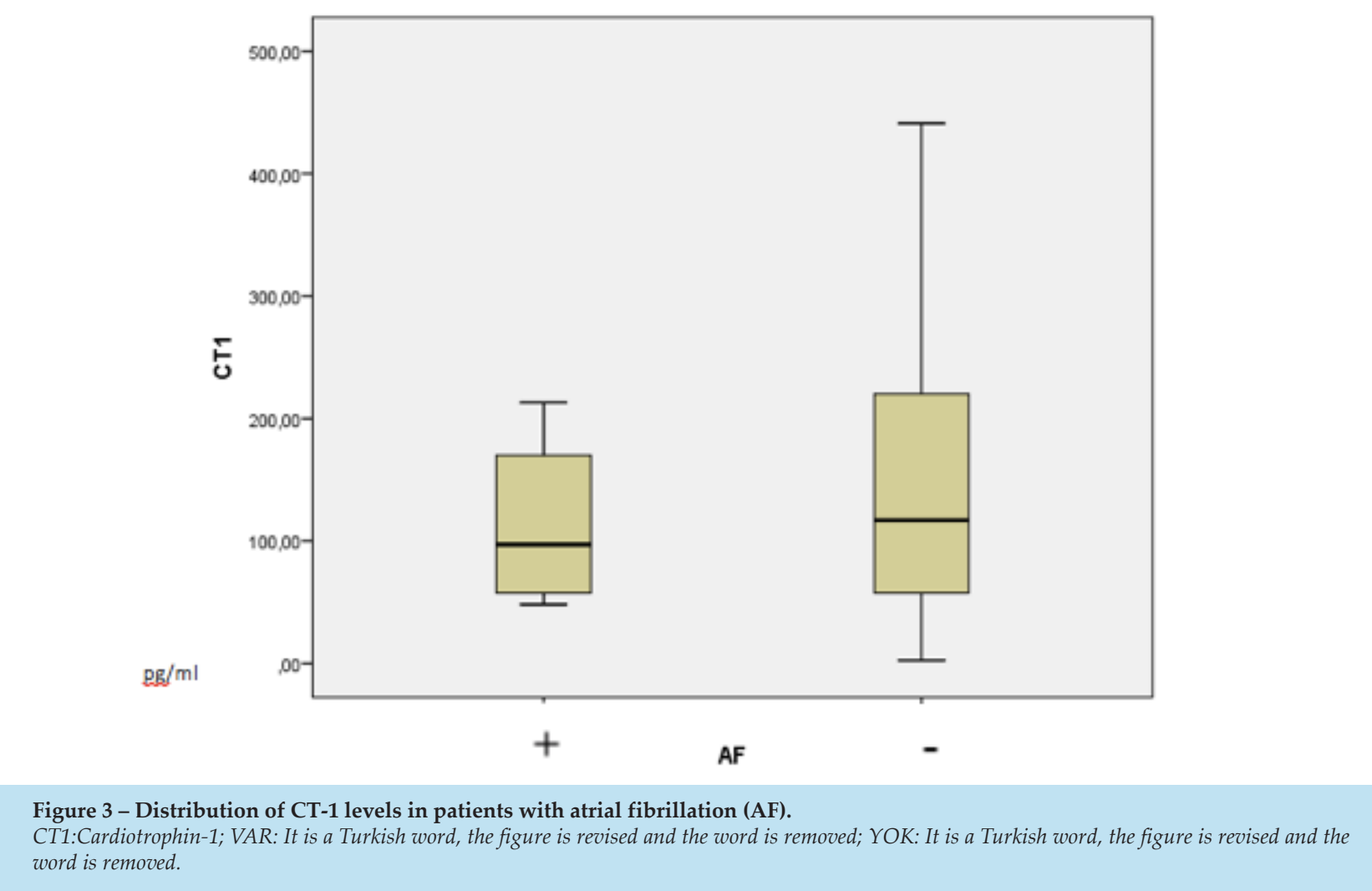

\begin{tabular}{|c|c|c|c|}
\hline & 0 . hour & 6. hour & $p$ value \\
\hline WBC (K/Ml) & $10.68 \pm 4.01$ & $11.62 \pm 3.29$ & $0.024^{*}$ \\
\hline HG (g/dl) & $12.90 \pm 1.77$ & $12.46 \pm 1.84$ & $0.022^{*}$ \\
\hline AST (IU/L) & $48.77 \pm 13.34$ & $56.45 \pm 18.32$ & $0.0045^{*}$ \\
\hline ALT (IU/L) & $26.85 \pm 11.89$ & $29.13 \pm 8.01$ & $0.0071^{*}$ \\
\hline CK (IU/L) & $\begin{array}{c}\text { Range: } 254-493 \\
\text { Median: } 372.5\end{array}$ & $\begin{array}{c}\text { Range: } 416-829 \\
\text { Median: } 712.3\end{array}$ & $0.0082^{* *}$ \\
\hline CK-MB (IU/L) & $48.08 \pm 24.5$ & $90.18 \pm 33.14$ & $0.0065^{*}$ \\
\hline $\mathrm{Tn}-\mathrm{T}(\mathrm{ng} / \mathrm{mL})$ & $\begin{array}{c}\text { Range: } 1354-2462 \\
\text { Median: } 1758.4\end{array}$ & $\begin{array}{c}\text { Range: } 2519-6128 \\
\text { Median: } 4732.6\end{array}$ & $0.0092^{* *}$ \\
\hline CT-1 (pg/mL) & $132.04 \pm 48.1$ & $322.19 \pm 98.12$ & $0.0084^{*}$ \\
\hline
\end{tabular}

the patient died on the 12th day of hospitalization at the cardiology intensive care unit. The control CT-1 levels were above the average values on admission and at the 6th hour control in this patient.

We have not come across any other complications (mechanical, ischemic and neurological complications etc.) of myocardial infarction, Hence, we could not evaluate the relationship between CT-1 levels and complications of myocardial infarction. However, according to the correlation between CT-1 levels and routine biomarkers for CAD a positive, significant correlation was observed with standard biomarkers of myocardial ischemia and CT-1 (Tables 3-6). 


\begin{tabular}{lcc}
\hline \multicolumn{3}{l}{ Table 4 - Correlation analysis for 0-hour CT-1 } \\
\hline 0.hour CT-1 & r value & p value \\
\hline 0. hour CK & 0.335 & 0.035 \\
\hline 0. hour CK-MB & 0.427 & 0.006 \\
\hline 0. hour Tn-T & 0.085 & 0.041 \\
\hline 6.hour CK-MB & 0.396 & 0.011 \\
\hline 6.hour CK & 0.372 & 0.018 \\
\hline 6.hour Tn-T & 0.064 & 0.096 \\
\hline 6.hour CT-1 & 0.702 & 0.000 \\
\hline $\begin{array}{l}\text { CK: Creatine kinase, CK-MB: Creatine kinase } M B, \text { Tn-T: Troponin- } T, \\
\text { CT-1:Cardiotrophin-1 }\end{array}$ & \\
\hline
\end{tabular}

\begin{tabular}{|c|c|c|}
\hline \multicolumn{3}{|c|}{$\begin{array}{l}\text { Table } 6 \text { - Correlation analysis for the } 6 \text { th hou } \\
\text { Troponin-T }\end{array}$} \\
\hline 6. hour Troponin-T & r value & $\mathrm{p}$ value \\
\hline 0.hour Tn-T & 0.976 & 0.000 \\
\hline 0.hour CT-1 & 0.064 & 0.036 \\
\hline 6.hour CT-1 & 0.011 & 0.044 \\
\hline 6.hour CK & 0.042 & 0.795 \\
\hline 6.hour CK-MB & 0.683 & 0.000 \\
\hline
\end{tabular}

\section{Discussion}

To the best of our knowledge, the current research is one of the preliminary studies in the literature comparing CT-1 levels with other cardiac markers in patients presenting to the clinic with ACS. The results of our study indicate that the CT-1 levels were significantly higher in the STEMI group compared to the other subgroups of ACS who were admitted to the hospital with chest pain.

$\mathrm{C}$-reactive protein, metalloproteinases, brain natriuretic protein (BNP) have been considered biomarkers of atherothrombotic risk, platelet activation and cardiac insufficiency. One of these newly investigated biomarkers in the recent years has been the CT- 1 molecule. This cytokine performs growth and differentiation activities through a unique receptor system comprising the interleukin 6 (IL-6) receptor and glycoprotein 130 (Gp130). Although the CT-1 molecule is found in the liver, adipose tissue and respiratory system, its predominant effect is on the heart as it is synthesized by the myocardium. It acts in myocardial protection by triggering proliferation with cell survival, shows its hemodynamic effects and

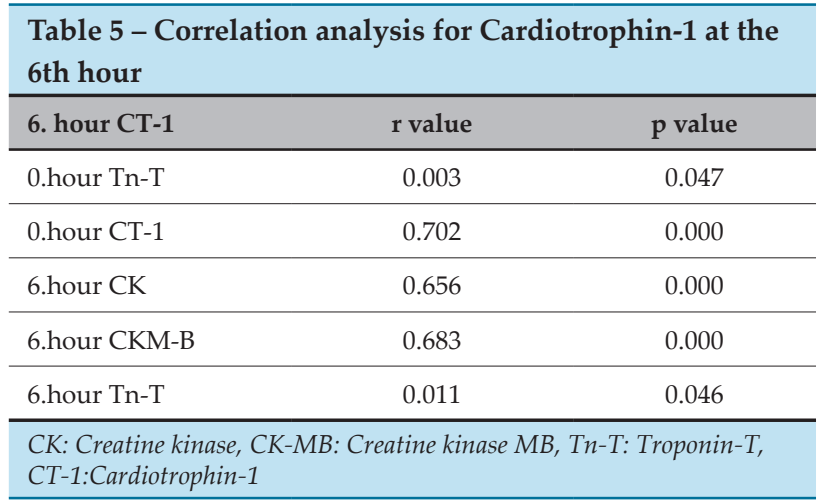

endocrine properties, and finally prepares the heart for pathological conditions. It actually induces myocyte hypertrophy and collagen synthesis. Studies have shown that CT- 1 inhibits cardiomyocyte apoptosis and plays a role in the survival and proliferation of embryonic cardiomyocytes. ${ }^{10}$ In previous studies, CT-1 protein was also found to be associated with hypertension, congestive heart failure and CAD. ${ }^{15}$

Khan et al., ${ }^{16}$ showed that CT-1 levels would be a prognostic biomarker in patients with acute myocardial infarction to indicate death and cardiac insufficiency. In one of our patients, cardiac arrest occurred on the 12th day of hospitalization and subsequently death. When the features of this patient at the first admission were examined, it was observed that the control CT-1 levels were above the average values on admission and at the 6th hour control, and that cardiac systolic dysfunction and cardiogenic shock were accompanied by acute renal insufficiency.

There is a close relationship between hypertension and ACS. ${ }^{17}$ CAD has 2-3 times higher incidence in hypertensive patients compared with normotensive people. Twenty-eight $(70 \%)$ of the 40 patients included in the study had hypertension. We failed to find a significant correlation between the hypertensive patients and CT-1 levels in our cohort, most probably attributed to the small sample size.

In another study by Martinez et al., ${ }^{18}$ on rats, a linear correlation was found between myocardial fibrosis and increased CT-1 levels. These findings showed that CT-1 level may provide useful prognostic value in heart failure. In our study, especially in patients with STEMI, CT-1 levels increased more than the other ACS groups, supporting its myocardial protective effects in terms of prognosis. 


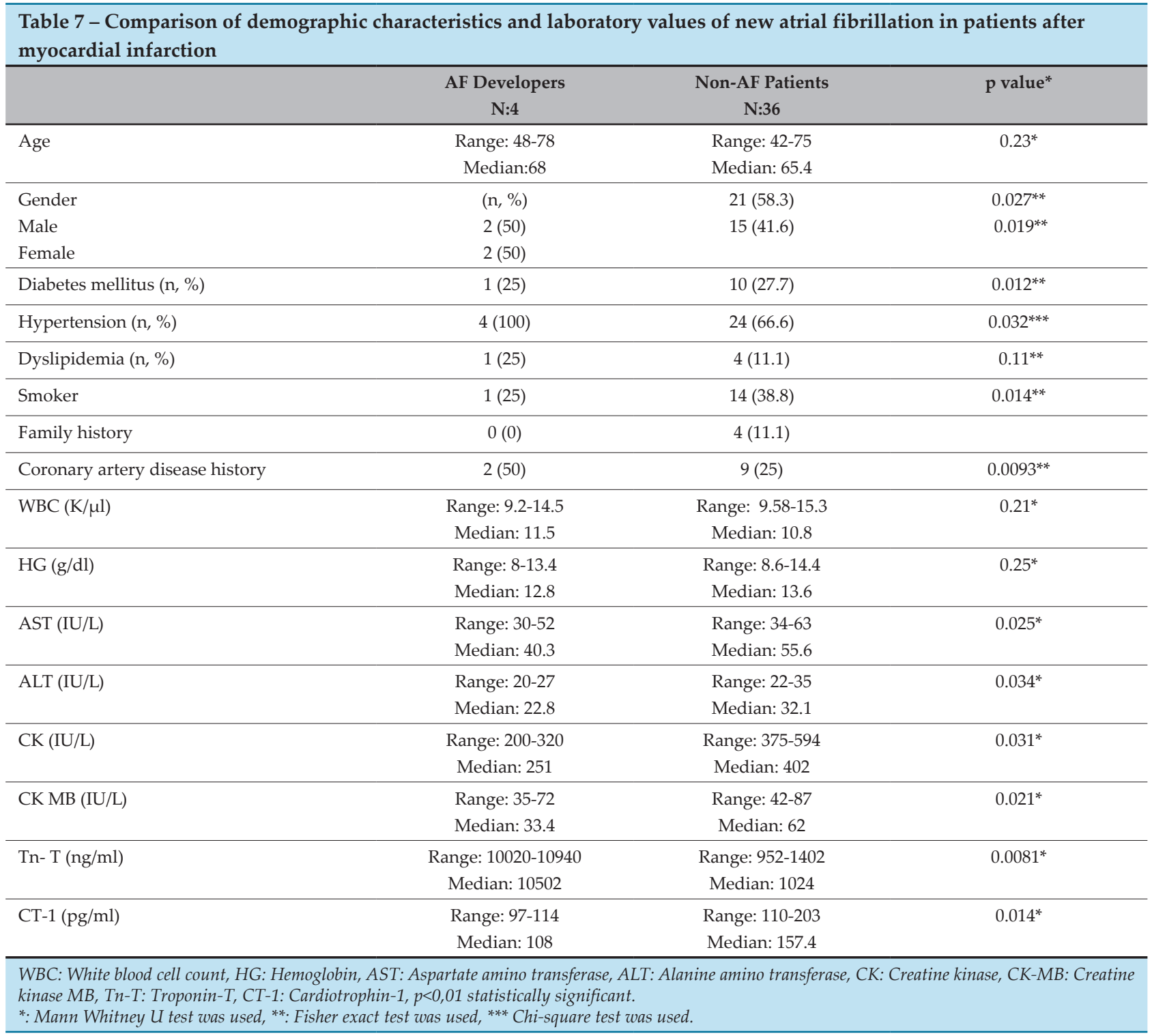

Altun et al. found a positive correlation between CT-1 levels and recurrence of AF after cardioversion in 32 patients with AF (19). In our study, AF was detected in 4 patients; but CT-1 levels were not different between groups with and without AF. In Altun et al., ${ }^{19}$ series a correlation between chronic fibrosis and CT-1 levels was detected, and it was proposed that increased CT-1 levels might be useful in detecting AF recurrence after cardioversion..$^{19} \mathrm{AF}$ was new onset in our 4 patients, and it could be the reason for not increasing CT-1 levels. The other reason for failure to detect a significant correlation might be the small number of patients experiencing $\mathrm{AF}$ in our cohort. On the contrary, our findings of not increasing CT-1 levels in acute onset AF may be a distinct marker and have prognostic value to rule out long-standing myocardial fibrosis as previously stated by Calabro et al. ${ }^{20}$

The Harmonizing Outcomes with Revascularization and Stents in Acute Myocardial Infarction (HORIZONAMI) study investigated the relationship between occult and overt infarction and cytokines in patients with STEMI who received paclitaxel-eluting stent implantation. The aim of this study was to determine whether biomarkers would be useful in predicting stent thrombosis after drug-eluting stent implantation. The study was the first to be conducted in this respect. Patients included in the study were followed up for a total of 3 years. A total of 26 biomarkers were measured at the beginning of the study and during the follow-up. In multivariate analysis, CT-1 was found to be associated with the target vessel 


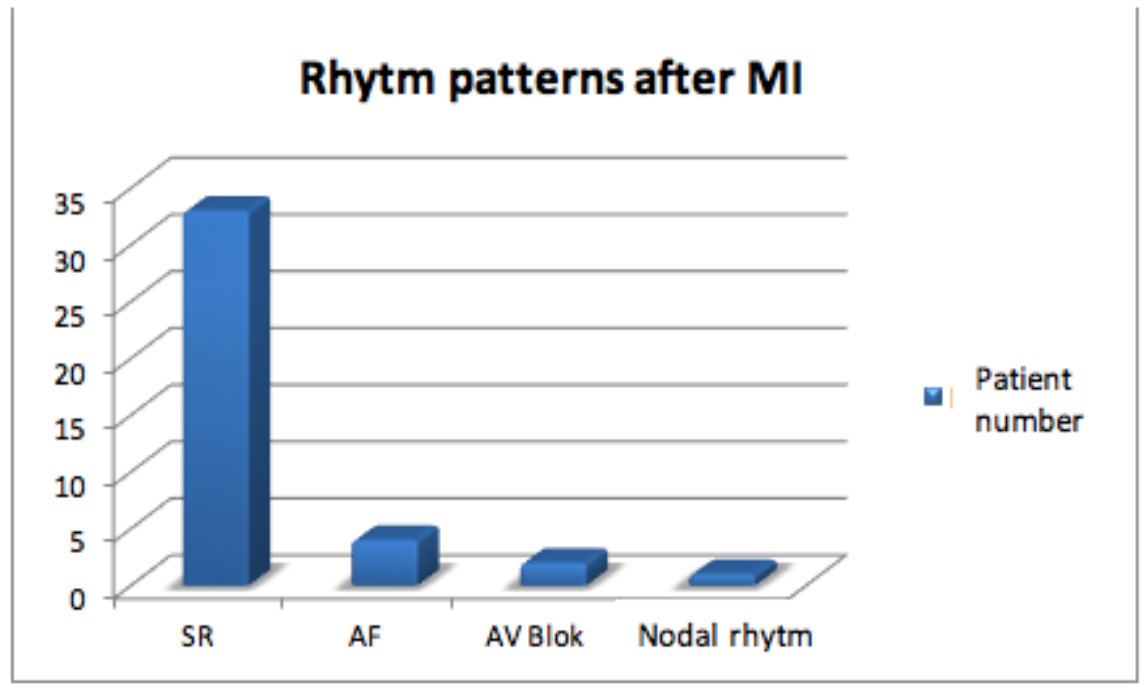

Figure 4 - Electrocardiogram (ECG) recordings of patients after myocardial infarction (MI).

revascularization independent to other biomarkers in late stent thrombosis. ${ }^{21}$

In their study, Bortolotti et al. showed that the most important cytokine that increases the survival of cardiac mesenchymal cells as graft in vivo had been the CT-1 (11). All these findings show how important CT-1 is in cardiac remodeling. Cardiac functions after acute myocardial infarction are very important in determining medical treatment. In this study, our aim was to focus on early markers of cardiac injury, determine the molecules that will increase the risk of early cardiac events and decide on the treatment plan.

\section{Limitations}

The major limitations of the study are small cohort size and short period follow up of the patients. Despite the small number of patients, the correlation analysis indicated the adequacy of CT-1 as a reliable marker in patients with ACS. Definitely additional serial blood tests at the follow-up would have added to the scientific strength of the manuscript.

\section{Conclusion}

Due to the increased incidence of cardiovascular events in the community, which leads to a long hospitalization and the increased incidence of mortality, there is an ongoing search for novel prognostic biomarkers. CT-1 was found to be increased in correlation with routine biomarkers CK, CK-MB and the levels of troponin also in our study, and high blood levels were detected especially in patients with STEMI. However, multicenter studies including a higher number of patients and patients from different regions of the world are warranted to better confirm the findings with CT-1.

\section{Author contributions}

Conception and design of the research: Polat $\mathrm{U}$, Aydinlar A, Caliskan S, Boyuk F, Unal O. Acquisition of data: Polat U. Analysis and interpretation of the data: Polat U, Aydinlar A, Caliskan S, Boyuk F, Unal O. Writing of the manuscript: Polat U. Critical revision of the manuscript for intellectual content: Polat U, Aydinlar A, Caliskan S, Boyuk F, Unal O.

\section{Potential Conflict of Interest}

No potential conflict of interest relevant to this article was reported.

\section{Sources of Funding}

There were no external funding sources for this study.

\section{Study Association}

This article is part of the thesis of Doctoral submitted by Ufuk Polat, from Uludag University Faculty of Medicine. 


\section{Ethics approval and consent to participate}

This study was approved by the Ethics Committee of the Uludag University Faculty of Medicine under the protocol number 2012-13/3. All the procedures in this study were in accordance with the 1975 Helsinki Declaration, updated in 2013. Informed consent was obtained from all participants included in the study.

\section{References}

1. Précoma DB, Oliveira GMM, Simão AF, Dutra OP, Coelho OR, Izar MCO, et al. Updated Cardiovascular Prevention Guideline of the Brazilian Society of Cardiology - 2019. Arq Bras Cardiol. 2019 Nov 4;113(4):787891. doi: 10.5935/abc.20190204.

2. American Heart Association. Heart diseases and stroke statistics - 2017. Circulation.2017;135(10):e146-e603.

3. Murray CJ, Lopez AD. Global mortality, disability, and the contribution of risk factors: Global Burden of Disease Study. Lancet. 1997; 349(9063):1436-42.]

4. Onat A, Ugur M, Çiçek G, Ayhan E, Doğan Y, Kaya H, et al. The Turkish Adult Risk Factor survey 2009: similar cardiovascular mortality in rural and urban areas. Turk Kardiyol Dern Ars.2010;38(3):159-63.

5. Önalan MA, Bahşeliyev Ş, Beyaz MO, Öztaş DM, Önal Y, Uğurlucan M, Tireli E. Karotis endarterektomi operasyonu geçiren hastalarda alt ekstremite periferik arter hastalığı sıklığının belirlenmesi. J Ist Faculty Med. 2020;83(1):35-41.

6. Stary HC, Chandler AB, Glagov S, Guyton, JR, Insull Jr W, Rosenfeld $\mathrm{ME}$, et al. A definition of initial, fatty streak, and intermediate lesions of atherosclerosis. A report from the Committee on Vascular lesions of the council on Arteriosclerosis, American Heart Association. Circulation. 1994; 89(5): 2462-78.

7. Katherine C. Michelis KC, Olin JW, Kadian-Dodov D, d'Escamard V, Kovacic JC. Coronary Artery Manifestations of Fibromuscular Dysplasia. J Am Coll Cardiol. 2014; 64(10): 1033-46

8. Farb A, Burke AP, Tang AL, Liang TY, Mannan P. Coronary plaque erosion without rupture into a lipid core. A frequent cause of coronary thrombosis in sudden coronary death. Circulation. 1996;93(7):1354-63.

9. Kumada M, Kihara S, Sumitsuji S, Kawamoto T, Matsumoto S, Ouchi N, et al. Coronary artery disease Association of hypoadiponectinemia with coronary disease in men. Arterioscler Thromb Vasc Biol.2003;23(1):85-9.

10. Hazama S, Eishi K, Yamachika S, Noguchi M, Ariyoshi T, Takai H, et al. Inflammatory response after coronary revascularization: off-pump versus on-pump (heparin-coated circuits and poly2methoxyethylacrylate-coated circuits). Ann Thorac Cardiovasc Surg. 2004;10(2):90-6.

11. Bortolotti F, Ruozi G, Falcione A, Doimo S, Dal Ferro M, Lesizza P, et al. In Vivo Functional Selection Identifies Cardiotrophin-1 as a Cardiac Engraftment Factor for Mesenchymal Stromal Cells. Circulation 2017;136(16):1509-24

12. Liao Z, Brar BK, Cai Q, Stephanou A, O'Leary RM, Pennica D, et al. Cardiotrophin-1 (CT-1) can protect the adult heart from injury when added both prior to ischaemia and at reperfusion. Cardiovasc Res. 2002;53(4):902-10.

13. Freed DH, Borowiec AM, Angelovska T, Dixon IM. Induction of protein synthesis in cardiac fibroblasts by cardiotrophin-1: integration of multiple signaling pathways. Cardiovasc Res. 2003;60(2):365-75.

14. Hamm CW, Braunwald E. A Classification of Unstable Angina Revisited Circulation. 2000; 102(1):118-22.

15. Pemberton CJ, Raudsepp SD, Yandle TG, Cameron VA, Richards AM. Plasma cardiotrophin-1 is elevated in human hypertension and stimulated by ventricular stretch. Cardiovasc Res. 2005;68(1):635-9.

16. Khan S, Kelly D, Quinn P, Davies JE, Ng LL. Cardiotrophin-1 predicts death or heart failure following acute myocardial infarction. J Card Fail 2006; 12(8):635-40.

17. Kannel WB. Blood pressure as a cardiovascular risk factor: prevention and treatment. JAMA 1996;275(20):1571-6.

18. Martínez-Martínez E, Brugnolaro C, Ibarrola J, Ravassa S, Buonafine M López B, et al. CT-1 (Cardiotrophin-1)-Gal-3 (Galectin-3) Axis in Cardiac Fibrosis and Inflammation. Hypertension. 2019;73(3):602-11.

19. Altun I, Pamukcu B, Yildiz CE, Can Arkaya S, Guz G, Yılmaz A, et al. Cardiotrophin-1: A new predictor of atrial fibrillation relapses after successful cardioversion. Bosn J Basic Med Sci. 2015;15(3):68-73.

20. Calabrò P, Limongelli G, Riegler L, Maddaloni V, Palmieri R, Golia E et al. Novel insights into the role of cardiotrophin-1 in cardiovascular diseases. J Mol Cell Cardiol. 2009; 46(2):142-8.

21. Claessen BE, Stone GW, Mehran R, Witzenbichler B, Brodie BR, Wöhrle J, et al. Relationship between biomarkers and subsequent clinical and angiographic restenosis after paclitaxel-eluting stents for treatment of STEMI: a HORIZONS-AMI substudy. J Thromb Thrombolysis 2012;34(2):165-79. 